\title{
Accurate Calculation Procedure for V-x Parameters of Hydrothermal Gold Ore Fluid Inclusions
}

\author{
Shixiang Yang ${ }^{1, *}$, Rui Sun ${ }^{2}$, Xiqiang Liu ${ }^{3}$, Zhao Liu ${ }^{4}$ and Jingyuan Wen ${ }^{1}$ \\ 1 Institute of Earth Sciences, China University of Geosciences (Beijing), Beijing 100083, China; \\ wenjingyuan@cugb.edu.cn \\ 2 Department of Geology, Northwest University, Xi'an 710069, China; ruisun@nwu.edu.cn \\ 3 Institute of Geochemistry, Chinese Academy of Sciences, Guiyang 550081, China; liuxiqiang@mail.gyig.ac.cn \\ 4 The oil field of PetroChina Changqing Oil Field Company, Xi'an 710000, China; \\ liuzh31_cq@petrochina.com.cn \\ * Correspondence: yangsx@cugb.edu.cn; Tel.: +86-10-8232-1306
}

Received: 1 October 2019; Accepted: 29 October 2019; Published: 31 October 2019

check for updates

\begin{abstract}
Determining the $\mathrm{V}-\mathrm{x}$ parameters of $\mathrm{H}_{2} \mathrm{O}-\mathrm{NaCl}-\mathrm{CO}_{2}$ fluid inclusions (total density of inclusions, gas content, homogenization pressure, etc.) is of great value for the exploration of hydrothermal deposits. However, previous accurate calculation methods are only applicable to $\mathrm{H}_{2} \mathrm{O}-\mathrm{NaCl}-\mathrm{CO}_{2}$ fluid inclusions with homogenization temperature above $300{ }^{\circ} \mathrm{C}$ and $\mathrm{CO}_{2}$ phase homogenization temperature above the $\mathrm{CO}_{2}$ clathrate melting temperature. In this paper, a new calculation method is proposed to accurately solve the $\mathrm{V}$-x parameters of $\mathrm{H}_{2} \mathrm{O}-\mathrm{NaCl}-\mathrm{CO}_{2}$ fluid inclusions with complete homogenization temperature lower than $300{ }^{\circ} \mathrm{C}$. The algorithm first determines the salinity of inclusions with respect to the melting temperature of $\mathrm{CO}_{2}$ clathrate and the partial homogenization temperature of the $\mathrm{CO}_{2}$ phase and then determines the internal pressure of inclusions when $\mathrm{CO}_{2}$ clathrate is completely melted. The V-x parameters of the inclusions are then iteratively solved. The new algorithm does not require a visual estimation of the volume fraction of the $\mathrm{CO}_{2}$ phase as an input parameter. It is possible to avoid the significant error brought about by traditional method of calculating the inclusion V-x parameters involving visual estimation of the $\mathrm{CO}_{2}$ phase volume fraction. A computer program is developed on the basis of the new method and is applied to the analysis of fluid inclusions in medium and low temperature hydrothermal gold ore.
\end{abstract}

Keywords: $\mathrm{H}_{2} \mathrm{O}-\mathrm{NaCl}-\mathrm{CO}_{2}$; fluid inclusion; V-x parameter; algorithm; calculation program

\section{Introduction}

Geological fluid, which is involved in and has a crucial effect on numerous geological processes, is among frontiers and hotspots in geoscience [1-4]. $\mathrm{NaCl}$ and $\mathrm{CO}_{2}$ are the most common solute components in various geological fluids. Many geological fluids can be approximated as $\mathrm{H}_{2} \mathrm{O}-\mathrm{CO}_{2}$ or $\mathrm{H}_{2} \mathrm{O}-\mathrm{NaCl}-\mathrm{CO}_{2}$ systems, such as hydrothermal gold ore-forming fluids, intermediate-grade metamorphic fluids, etc. Therefore, determining the physical and chemical parameters, e.g., density, salinity, composition, and homogenization pressure of $\mathrm{H}_{2} \mathrm{O}-\mathrm{NaCl}-\mathrm{CO}_{2}$ inclusions, is one of the important foundations for studying the source and evolution of ore-forming fluids and exploring the formation mechanism of hydrothermal deposits [5-9].

Previous studies have shown that most hydrothermal gold ore-forming fluids have medium to low salinity ( $\mathrm{NaCl}$ less than 6-10 wt \%) and relatively high $\mathrm{CO}_{2}$ content, and the complete homogenization temperature of the inclusions is between $200-400{ }^{\circ} \mathrm{C}$ [9-11]. At room temperature, the inclusions are either gas-liquid-liquid or gas-liquid, and lack halite daughter minerals. $\mathrm{H}_{2} \mathrm{~S}$ and $\mathrm{N}_{2}$ are also very low. Therefore, a V-x parameter calculation program for the $\mathrm{H}_{2} \mathrm{O}-\mathrm{NaCl}-\mathrm{CO}_{2}$ inclusions is adequate for the research of hydrothermal gold ore fluid inclusion. 
The thermodynamic model and calculation method are both necessary for the development of the calculation program. The determination of V-x parameters of the inclusions requires accurate calculations of the P-V-T-x and gas-liquid equilibrium composition of the $\mathrm{H}_{2} \mathrm{O}-\mathrm{NaCl}-\mathrm{CO}_{2}$ fluid system at $0-400{ }^{\circ} \mathrm{C}, 0-3000$ bar. Previous state equations for $\mathrm{H}_{2} \mathrm{O}-\mathrm{NaCl}-\mathrm{CO}_{2}-\mathrm{CH}_{4}$ system at medium-high temperature $\left(T>300^{\circ} \mathrm{C}\right)$ or medium-low temperature equations [12-14], as well as the $\mathrm{CO}_{2}$ solubility model could basically meet the calculation requirement [14-16]. For the latter, Song's [17] method is adequate for the calculation of $\mathrm{H}_{2} \mathrm{O}-\mathrm{NaCl}-\mathrm{CO}_{2}$ inclusions where the $\mathrm{CO}_{2}$ phase homogenization temperature is higher than the $\mathrm{CO}_{2}$ clathrate melting temperature. Mao et al. [18] proposed a method for the calculation of $\mathrm{H}_{2} \mathrm{O}-\mathrm{NaCl}-\mathrm{CO}_{2}$ inclusions with complete homogenization to liquid phase and homogenization pressure not higher than 1500 bar, which is based on the model of Song [17]. For the calculation of the $\mathrm{V}$-x parameter of the $\mathrm{H}_{2} \mathrm{O}-\mathrm{NaCl}-\mathrm{CO}_{2}$ inclusions whose $\mathrm{CO}_{2}$ phase homogenization temperature is lower than the melting temperature of the $\mathrm{CO}_{2}$ clathrate, a valid algorithm that does not require a visual estimation of gas-liquid ratiois still absent.

This study aims to solve the above problems by developing a computer program that can accurately calculate the $\mathrm{V}$-x parameters of $\mathrm{H}_{2} \mathrm{O}-\mathrm{NaCl}-\mathrm{CO}_{2}$ inclusions. Two major contributions are included in this study, as described below:

1. A new iterative algorithm is proposed to solve the $\mathrm{V}$-x parameters of $\mathrm{H}_{2} \mathrm{O}-\mathrm{NaCl}-\mathrm{CO}_{2}$ inclusions with a $\mathrm{CO}_{2}$ phase homogenization temperature lower than the $\mathrm{CO}_{2}$ clathrate melting temperature and to develop a calculation program. This new algorithm only takes the temperature measurement data as the input parameter and does not need to visually measure the volume fraction of the $\mathrm{CO}_{2}$ phase.

2. A new application is developed that can accurately calculate the V-x parameters of $\mathrm{H}_{2} \mathrm{O}-\mathrm{NaCl}-\mathrm{CO}_{2}$ inclusions, which is based on the algorithms of Song et al. [17] and this paper. The thermodynamic properties of the $\mathrm{H}_{2} \mathrm{O}-\mathrm{NaCl}-\mathrm{CO}_{2}$ system with temperatures above $300{ }^{\circ} \mathrm{C}$ and temperatures below $300{ }^{\circ} \mathrm{C}$ were calculated using the equations established by Duan et al. [12], Sun and Dubessy [13]. The application is valid at a full homogenization temperature range of $200-450{ }^{\circ} \mathrm{C}$, and is suitable for both situations in which $\mathrm{CO}_{2}$ phase homogenization temperature is either higher or lower than $\mathrm{CO}_{2}$ clathrate melting temperature, with no halite daughter minerals present.

\section{Calculation Method}

\subsection{Salinity Calculation of $\mathrm{H}_{2} \mathrm{O}-\mathrm{NaCl}-\mathrm{CO}_{2}$ Fluid Inclusions}

For $\mathrm{H}_{2} \mathrm{O}-\mathrm{NaCl}-\mathrm{CO}_{2}$ inclusions, salinity is generally expressed in mass fraction or mass percentage $\mathrm{S}$, representing the mass fraction of $\mathrm{NaCl}$ in $\mathrm{H}_{2} \mathrm{O}-\mathrm{NaCl}$ solution. At room temperature, the $\mathrm{H}_{2} \mathrm{O}-\mathrm{NaCl}-\mathrm{CO}_{2}$ inclusions generally appear in two or three phases. The corresponding salinity calculation method will be introduced below with respect to these two different situations.

\subsubsection{Salinity Calculation of Three-Phase $\mathrm{H}_{2} \mathrm{O}-\mathrm{NaCl}-\mathrm{CO}_{2}$ Inclusions at Room Temperature}

At room temperature, three-phase $\mathrm{H}_{2} \mathrm{O}-\mathrm{NaCl}-\mathrm{CO}_{2}$ inclusions (aqueous phase $+\mathrm{CO}_{2}$ liquid phase $+\mathrm{CO}_{2}$ gas phase) cool down to form $\mathrm{CO}_{2}$ clathrate. After re-heating, the melting temperature of the $\mathrm{CO}_{2}$ clathrate will be lower than the homogenization temperature of the $\mathrm{CO}_{2}$ phase. Therefore, $\mathrm{CO}_{2}$ clathrate in the inclusion disappeared by heating so that the salinity of the inclusion could be determined with respect to the temperature. During the heating, the $\mathrm{CO}_{2}$ clathrate disappears and the system is in four-phase equilibrium. According to the Gibbs phase rule:

$$
F=C-\varphi+2
$$

the number of components $C=3$, the number of phases $\varphi=4$, the four-phase degree of freedom $F=1$, the salinity then has a one-to-one correspondence to the melting temperature of the clathrate, and the $\mathrm{NaCl}$ content of the aqueous phase is also determined when melting temperature is determined. In addition, in the case of lower temperature, the content of $\mathrm{NaCl}$ and water vapor in the $\mathrm{CO}_{2}$ gas phase (bubble) and $\mathrm{CO}_{2}$ liquid phase is negligible, and the $\mathrm{NaCl}$ content in the aqueous phase could 
be used to calculate the salinity of the entire inclusion. Salinity could be calculated by the equation below $[19,20]$ :

$$
\mathrm{S}(\mathrm{wt} \%)=0.00098241 \times(10-T) \times\left(T^{2}+45.385 T+1588.75\right)
$$

where $T$ is the melting temperature of $\mathrm{CO}_{2}$ hydrate $\left(-10-10^{\circ} \mathrm{C}\right)$. This equation is valid in the $\mathrm{NaCl}$ salinity range of $0-24.2 \mathrm{wt} \%$.

\subsubsection{Salinity Calculation of Two-Phase $\mathrm{H}_{2} \mathrm{O}-\mathrm{NaCl}-\mathrm{CO}_{2}$ Inclusions at Room Temperature}

The method above is not valid for the determination of salinity for $\mathrm{H}_{2} \mathrm{O}-\mathrm{NaCl}-\mathrm{CO}_{2}$ fluid inclusions exhibiting two phases at room temperature (aqueous phase $+\mathrm{CO}_{2}$ liquid phase or $\mathrm{CO}_{2}$ gas phase). When the inclusions cool down, $\mathrm{CO}_{2}$ hydrate will also form. When the system is heated, the hydrate will disappear at a certain temperature. At this time, the inclusion system is on the three-phase equilibrium interface. Since the number of components is $C=3$, the number of phases is $\varphi=4$, and the degree of freedom of the system is $F=2$, which means that the salinity changes not only with temperature but also with pressure. Then the aforementioned method for determining the salinity of three-phase $\mathrm{H}_{2} \mathrm{O}-\mathrm{NaCl}-\mathrm{CO}_{2}$ inclusions is no longer applicable.

The following two calculation methods are mainly used for this occasion. The first method was proposed by Diamond [21], which determines the salinity in combination with the hydrate melting temperature and the partial homogenization temperature of the $\mathrm{CO}_{2}$ measured in the metastable state. When the $\mathrm{CO}_{2}$ gas phase and the liquid phase are homogeneous to the gas phase, the salinity is calculated as follow:

$$
\mathrm{S}(\mathrm{wt} \%)=15.6151-0.03627 x+0.00164 x^{2}-0.949 y-0.00287 x y-0.02464 y^{2}-0.00107 x y^{2}-0.00222 y^{3}
$$

$x$ is the partial homogenization temperature of the $\mathrm{CO}_{2}$ phase, and the range of application is between $-20{ }^{\circ} \mathrm{C}$ to $10^{\circ} \mathrm{C} . y$ is the melting temperature of the hydrate and is valid between $-5^{\circ} \mathrm{C}$ to $13^{\circ} \mathrm{C}$. The range of salinity $\mathrm{S}$ is $0-21 \mathrm{wt} \% \mathrm{NaCl}$ (relative to the binary $\mathrm{H}_{2} \mathrm{O}-\mathrm{NaCl}$ subsystem without $\mathrm{CO}_{2}$ ). When the $\mathrm{CO}_{2}$ gas phase and the liquid phase are homogeneous to the liquid phase, the salinity is calculated as follow:

$$
\mathrm{S}(\mathrm{wt} \%)=15.6151-0.065705 x+0.00778 x^{2}-1.05135 y-0.02687 x y-0.04717 y^{2}-0.00138 x y^{2}-0.00411 y^{3}
$$

The valid range of $x$ and $S$ is the same as the previous equation while $y$ is valid between $-8{ }^{\circ} \mathrm{C}$ to $10{ }^{\circ} \mathrm{C}$.

The second method, which is proposed by Fall et al. [22], determines the $\mathrm{CO}_{2}$ phase pressure according to the carbon dioxide Fermi peak displacement method, and also determines the $\mathrm{NaCl}$ content according to the gas hydrate three-phase equilibrium model by Bakker [23], Duan and Sun [15]. It brings smaller salinity error for $\mathrm{H}_{2} \mathrm{O}-\mathrm{NaCl}-\mathrm{CO}_{2}$ two-phase inclusion in which $\mathrm{CO}_{2}$ is a liquid phase $(0.3 \mathrm{wt} \%)$ and much more significant error for those in which $\mathrm{CO}_{2}$ exhibits gas phase $(\sim 3.2 \mathrm{wt} \%)$

\subsection{Calculation Method of $\mathrm{V}-x$ Parameters of $\mathrm{H}_{2} \mathrm{O}-\mathrm{NaCl}-\mathrm{CO}_{2}$ Inclusions}

For single-component fluid inclusions, the microthermometry measurement data can be substituted into the formula to calculate the total density of inclusions and homogenization pressure. For ternary system fluid inclusions, the total density, composition, homogenization pressure and other parameters need to be determined by means of more complex thermodynamic calculation models or diagrams.

The V-x parameter depends on the thermodynamic properties of the fluid system under different temperature and pressure conditions. A few of them can be calculated by simple formulas, while for the rest, an accurate solution can only be provided by thermodynamic models with sound theoretical basis. Due to the non-ideality of the system, there are few equations that can accurately describe the thermodynamic properties of $\mathrm{H}_{2} \mathrm{O}-\mathrm{NaCl}-\mathrm{CO}_{2}$ systems. Parameters and the corresponding models include (1) Gas-liquid phase equilibrium composition and density of $\mathrm{H}_{2} \mathrm{O}-\mathrm{NaCl}-\mathrm{CO}_{2}$ ternary system 
at the homogenization temperature are calculated by equation established by Duan et al. [12,14], Sun and Dubessy [13]. (2) Solubility of $\mathrm{CO}_{2}$ in aqueous sodium chloride solution at room temperature is described by the concentration of $\mathrm{CO}_{2}$ in aqueous $\mathrm{NaCl}$ solution, which could be provided by the $\mathrm{CO}_{2}$ solubility model established and improved by Duan and collaborators [14-16,24], and the density of aqueous solutions described by the Pitzer's [25] activity coefficient model. (3) Triple-phase equilibrium pressure of $\mathrm{CO}_{2}$ clathrate is determined by the equilibrium model established by Duan and Sun [15].

\subsubsection{Traditional Algorithm for V-x Parameters of $\mathrm{H}_{2} \mathrm{O}-\mathrm{NaCl}-\mathrm{CO}_{2}$ Fluid Inclusions}

As mentioned above, the salinity of the $\mathrm{H}_{2} \mathrm{O}-\mathrm{NaCl}-\mathrm{CO}_{2}$ fluid inclusions can be determined by the melting temperature of the $\mathrm{CO}_{2}$ clathrate, but there is no simple calculation method for the $\mathrm{CO}_{2}$ content of the inclusions. It is generally necessary to visually estimate the volume ratio of the $\mathrm{CO}_{2}$ phase to the aqueous phase, and then the homogenization pressure and isometrics of $\mathrm{H}_{2} \mathrm{O}-\mathrm{NaCl}-\mathrm{CO}_{2}$ inclusions can be obtained by using the appropriate equation of state on the basis of density, composition and the estimated homogenization temperature. Nonetheless, the visual volume fraction inevitably produces large errors, giving rise to inaccurate calculation results of parameters [26,27].

Combined with theoretical calculations, Schwarz [28] plotted the V-x diagram of $\mathrm{H}_{2} \mathrm{O}-\mathrm{CO}_{2}$ inclusions without $\mathrm{NaCl}$ and $\mathrm{H}_{2} \mathrm{O}-\mathrm{NaCl}-\mathrm{CO}_{2}$ inclusions with a salinity of $6 \mathrm{wt} \%$. Bakker and Diamond $[29,30]$ also mapped the $\mathrm{V}-\mathrm{x}$ of $\mathrm{H}_{2} \mathrm{O}-\mathrm{CO}_{2}$ inclusions based on experimental data published by Sterner and Bodnar [31]. Although the using of these diagrams does not need a visual estimation of the volume fraction of the $\mathrm{CO}_{2}$ phase, the accuracy is poor in the low temperature region, and the applicable range of salinity is small.

\subsubsection{Iterative Calculation Method for $\mathrm{V}-\mathrm{x}$ Parameters of $\mathrm{H}_{2} \mathrm{O}-\mathrm{NaCl}-\mathrm{CO}_{2}$ Fluid Inclusions at Room Temperature}

The phase volume of a $\mathrm{H}_{2} \mathrm{O}-\mathrm{NaCl}-\mathrm{CO}_{2}$ fluid inclusion is limited by the density, complete homogenization temperature and homogenization of the $\mathrm{CO}_{2}$ phase due to that the inclusion is a closed system with constant volume. Parry [32] proposed an iterative calculation method to solve the $\mathrm{CO}_{2}$ content and total density of the three-phase inclusions of $\mathrm{H}_{2} \mathrm{O}-\mathrm{NaCl}-\mathrm{CO}_{2}$ system. This method used the Bowers-Helgeson [33] equation to calculate the fluid thermodynamic parameters (gas-liquid phase equilibrium composition, gas phase, and aqueous phase density, etc.) required during the iterative process. Parry's method does not need to visually measure the volume or phase proportion of the inclusions, and density and $\mathrm{X}_{\mathrm{CO} 2}$ could be calculated using iterative method with the measurement of $T_{\mathrm{h}, \mathrm{CO} 2}, \mathrm{~S}$, and $T_{\mathrm{h}}$. Due to the Bowers-Helgeson equation, Parry's iterative algorithm can be used to calculate the $\mathrm{V}$-x parameters of $\mathrm{H}_{2} \mathrm{O}-\mathrm{NaCl}-\mathrm{CO}_{2}$ fluid inclusions with a homogenization temperature above $300^{\circ} \mathrm{C}$. However, Parry's method ignores the solubility of $\mathrm{CO}_{2}$ in $\mathrm{NaCl}$ aqueous solution, so the mathematical function of $X_{\mathrm{CO} 2}$ constructed and the calculated $X_{\mathrm{CO} 2}$ is not sufficiently accurate, and then the pressure error calculated by iterative calculation is ineligible. Furthermore, Parry's method cannot be applied for the $\mathrm{H}_{2} \mathrm{O}-\mathrm{NaCl}-\mathrm{CO}_{2}$ system at $0-300{ }^{\circ} \mathrm{C}$, due to the lack of validated fluid thermodynamic functions over this temperature range.

Liu and Shen [6], and Song [17] take into account the solubility of $\mathrm{CO}_{2}$ in aqueous sodium chloride solution at room temperature and improved the calculation accuracy of the Parry method. Song et al. [17] also used the more accurate $\mathrm{H}_{2} \mathrm{O}-\mathrm{NaCl}-\mathrm{CO}_{2}$ system state equation (DMW95 equation) established by Duan et al. [12] instead of the Bowers-Helgeson [17] equation. DMW95 is a state equation capable of accurately predicating P-V-T-X, phase equilibria, solubility, and activity of the $\mathrm{H}_{2} \mathrm{O}-\mathrm{NaCl}-\mathrm{CO}_{2}$ system. Since the DMW95 equation is only applicable to high temperature $\left(\mathrm{T}>300{ }^{\circ} \mathrm{C}\right) \mathrm{H}_{2} \mathrm{O}-\mathrm{NaCl}-\mathrm{CO}_{2}$ system, this improved calculation method is still not valid at complete homogenization temperature below $300^{\circ} \mathrm{C}$.

On the basis of Song's method, $\mathrm{Xi}$ et al. [34]. proposed that the dissolved amount of $\mathrm{CO}_{2}$ in aqueous solution $\mathrm{M}_{\mathrm{CO} 2}$ can be calculated by the solubility model proposed by Duan and Sun $[14,35]$. This method can only be applied to $\mathrm{H}_{2} \mathrm{O}-\mathrm{NaCl}-\mathrm{CO}_{2}$ inclusions in which the $\mathrm{CO}_{2}$ partial homogenization 
temperature is higher than the melting temperature of the clathrate, and the halite daughter minerals are absent. The inclusion should also be completely homogeneous to aqueous solutions. Xi et al. [34] also suggested that for $\mathrm{H}_{2} \mathrm{O}-\mathrm{NaCl}-\mathrm{CO}_{2}$ inclusions with complete homogenization temperature below $300{ }^{\circ} \mathrm{C}$ and salinity below $4 \%$, the ternary system can be approximated as a $\mathrm{H}_{2} \mathrm{O}-\mathrm{CO}_{2}$ binary system, which expands the applicable range of temperature and pressure of the method.

$\mathrm{Xu}$ et al. [36] combined the improved algorithms of Song with the state equation established by Mao et al. [37] and developed an application capable of calculating V-x parameters of $\mathrm{CO}_{2}-\mathrm{H}_{2} \mathrm{O}$ fluid inclusions with a complete homogenization temperature below $350{ }^{\circ} \mathrm{C}$, homogenization pressure below $100 \mathrm{MPa}$, which are completely homogenized to liquid phase.

Mao et al. [18] proposed a new algorithm for calculating the $\mathrm{V}$-x parameters of $\mathrm{H}_{2} \mathrm{O}-\mathrm{NaCl}-\mathrm{CO}_{2}$ inclusions. The method uses the improved $\mathrm{CO}_{2}$ solubility model of them in combination with the previously established aqueous solution density model to calculate the relevant thermodynamic properties of the $\mathrm{H}_{2} \mathrm{O}-\mathrm{NaCl}-\mathrm{CO}_{2}$ system. A calculation program is also developed based on this new algorithm, which applies to a maximum homogenization temperature of $723 \mathrm{~K}$, but only for $\mathrm{H}_{2} \mathrm{O}-\mathrm{NaCl}-\mathrm{CO}_{2}$ inclusions that are completely homogeneous to the liquid phase [18].

\section{Calculation Program Description}

\subsection{A New Algorithm for $\mathrm{V}$-x Parameters of $\mathrm{H}_{2} \mathrm{O}-\mathrm{NaCl}-\mathrm{CO}_{2}$ Two-Phase Inclusions at Room Temperature}

As mentioned above, the iterative method initiated by Parry [32] and further improved by Song et al. [17] is only applicable to $\mathrm{H}_{2} \mathrm{O}-\mathrm{NaCl}-\mathrm{CO}_{2}$ three-phase inclusions without halite daughter minerals, and is not suitable for the two-phase inclusion of $\mathrm{H}_{2} \mathrm{O}-\mathrm{NaCl}-\mathrm{CO}_{2}$, in which the homogenization temperature of the $\mathrm{CO}_{2}$ phase is lower than the melting temperature of the $\mathrm{CO}_{2}$ clathrate.

This study proposes a new iterative algorithm to accurately calculate the V-x parameters of the $\mathrm{H}_{2} \mathrm{O}-\mathrm{NaCl}-\mathrm{CO}_{2}$ two-phase inclusion. The algorithm first uses the method of Diamond [21] to determine the salinity of $\mathrm{H}_{2} \mathrm{O}-\mathrm{NaCl}-\mathrm{CO}_{2}$ two-phase inclusions with respect to the melting temperature of $\mathrm{CO}_{2}$ clathrate and the partial homogenization temperature of $\mathrm{CO}_{2}$ phase measured under metastable state, and uses the three-phase equilibrium calculation model of $\mathrm{CO}_{2}$ hydrate established by Duan and Sun [15] to determine the internal pressure of inclusions when $\mathrm{CO}_{2}$ clathrate is completely melted. Then, the V-x parameters of the inclusions are iteratively solved by the relationship between the phase change and the volume change when the $\mathrm{CO}_{2}$ clathrate is melted and the inclusions are completely homogenized. The new algorithm also does not require a visual estimation of the volume fraction of the $\mathrm{CO}_{2}$ phase as an input parameter. Tables 1 and 2 provide a brief description of the input and output parameters of the method and program

Table 1. Input parameter of the program for $\mathrm{H}_{2} \mathrm{O}-\mathrm{NaC}-\mathrm{CO}_{2}$ inclusion.

\begin{tabular}{ccc}
\hline Parameter Symbol & Description & Allowed Input Range \\
\hline$T_{\mathrm{h}, \mathrm{CO} 2}$ & Partial homogenization temperature of $\mathrm{CO}_{2}$ phase & $253-304.2 \mathrm{~K}$ \\
$T_{\mathrm{m}, \mathrm{cla}}$ & Melting temperature of $\mathrm{CO}_{2}$ clathrate & $264-283.2 \mathrm{~K}$ \\
$T_{\mathrm{h}}$ & Complete homogenization temperature of the inclusion & $473-723 \mathrm{~K}$ \\
\hline
\end{tabular}

Table 2. Output parameters of the program for $\mathrm{H}_{2} \mathrm{O}-\mathrm{NaCl}-\mathrm{CO}_{2}$ inclusions.

\begin{tabular}{cc}
\hline Parameter Symbol & Description \\
$\mathrm{V}_{\mathrm{m}}$ & Molecular volume of inclusion, $\mathrm{cm}^{3} / \mathrm{mol}$ \\
$X_{\mathrm{CO} 2}$ & Total $\mathrm{CO}_{2}$ content of the inclusions, expressed in mole fraction \\
$X_{\mathrm{H} 2 \mathrm{O}}$ & Total water content of the inclusion, expressed in mole fraction \\
$X_{\mathrm{NaCl}}$ & Total $\mathrm{NaCl}$ content of the inclusion, expressed in mole fraction \\
$T_{\mathrm{h}}$ & Complete homogenization temperature of the inclusion, $\mathrm{K}$ \\
$P_{\mathrm{hom}}$ & Homogenization pressure of the inclusion, bar \\
$\Phi_{\mathrm{CO} 2}$ & Volume fraction of $\mathrm{CO}_{2}$ gas phase in inclusions after $\mathrm{CO}_{2}$ clathrate melting \\
\hline
\end{tabular}


The specific iterative steps of the algorithm, as shown in Figure 1, are described as follows:

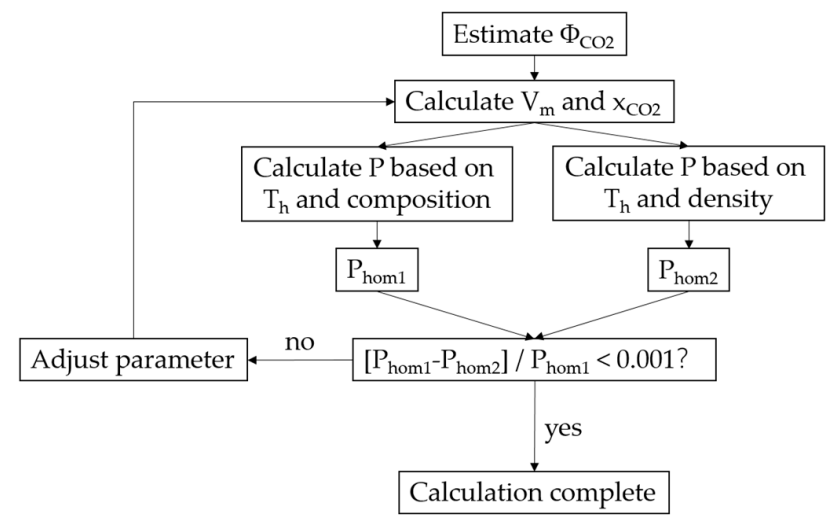

Figure 1. Flowchart for the calculation of V-x properties of two-phase $\mathrm{CO}_{2}-\mathrm{H}_{2} \mathrm{O}-\mathrm{NaCl}$ fluid inclusions.

1. After determining the salinity of the inclusions, the internal pressure of the inclusions after the carbon dioxide hydrate is completely melted is determined according to the gas hydrate three-phase equilibrium model, and then the density of the $\mathrm{CO}_{2}$ phase and the aqueous phase at this temperature are calculated using a proper thermodynamic model.

2. Calculating the total density (or molar volume) and $\mathrm{CO}_{2}$ concentration $X_{\mathrm{CO} 2}$ of the inclusion based on an initial estimation of $\Phi_{\mathrm{CO} 2}$.

3. Determining the pressure $P_{\text {homl }}$ at which the inclusions are at homogenization temperature $T_{\mathrm{h}}$, which refers to the minimum pressure at which the solution or gas phase is saturated at $T_{\mathrm{h}}$.

4. Calculating the pressure $P_{\text {homl2 }}$ at which the inclusions with certain composition and total density exhibit a single phase at the homogenization temperature.

5. If $P_{\text {homl }}$ and $P_{\text {homl2 }}$ are significantly different, change $\Phi_{\mathrm{CO} 2}$ and re-calculate the total density (or molar volume) and $X_{\mathrm{CO} 2}$ until the calculated relative difference of $P_{\text {homl }}$ and $P_{\text {homl2 }}$ is less than $0.1 \%$. At this time, the final total density, $X_{\mathrm{CO} 2}$, and $\Phi_{\mathrm{CO} 2}$ are obtained.

The above step 3 needs to calculate the gas-liquid equilibrium composition of the $\mathrm{H}_{2} \mathrm{O}-\mathrm{NaCl}-\mathrm{CO}_{2}$ system on the basis of a suitable equation of state, and step 4 requires the calculation of the P-V-T-x of the $\mathrm{H}_{2} \mathrm{O}-\mathrm{NaCl}-\mathrm{CO}_{2}$ system. The DMW95 equation is used when $T_{\mathrm{h}}>573 \mathrm{~K}$, while the equation of state for the medium-low temperature $\mathrm{H}_{2} \mathrm{O}-\mathrm{NaCl}-\mathrm{CO}_{2}$ system established by Sun and Dubessy [13] is applicable when $T_{\mathrm{h}} \leq 573 \mathrm{~K}$.

\section{2. $\mathrm{H}_{2} \mathrm{O}-\mathrm{NaCl}-\mathrm{CO}_{2}$ Inclusion Parameter Calculation Program Description}

Combining the iterative algorithm for calculating the V-x parameters of $\mathrm{H}_{2} \mathrm{O}-\mathrm{NaCl}-\mathrm{CO}_{2}$ inclusions with the related thermodynamic model introduced above, a computer program for the accurate calculation of $\mathrm{V}-\mathrm{x}$ parameters of $\mathrm{H}_{2} \mathrm{O}-\mathrm{NaCl}-\mathrm{CO}_{2}$ inclusions is written in FORTRAN90 language, which only takes microthermometry measurement data as input parameters with no gas phase volume fraction required. Some calculation examples were also given below.

\subsubsection{Program Function}

An important feature of the calculation program developed in this study is that the input parameters are all microthermometry measurement data without visually measuring the $\mathrm{CO}_{2}$ phase volume fraction. The Raman peak displacement of $\mathrm{CO}_{2}$ is also not required as an input parameter to determine the internal pressure and composition of the inclusion. In this study, the improved algorithm of Song et al. [17] was used to calculate the V-x parameters of $\mathrm{H}_{2} \mathrm{O}-\mathrm{NaCl}-\mathrm{CO}_{2}$ inclusions in which the partial homogenization temperature of the $\mathrm{CO}_{2}$ phase is higher than the melting temperature of $\mathrm{CO}_{2}$ clathrate. For the $\mathrm{V}-\mathrm{x}$ parameters of the $\mathrm{H}_{2} \mathrm{O}-\mathrm{NaCl}-\mathrm{CO}_{2}$ inclusions where the $\mathrm{CO}_{2}$ phase partial homogenization temperature is lower than the $\mathrm{CO}_{2}$ clathrate melting temperature, the new algorithm 
proposed in this study is applied, which is not only suitable for three-phase $\mathrm{H}_{2} \mathrm{O}-\mathrm{NaCl}-\mathrm{CO}_{2}$ inclusions but also for two-phase $\mathrm{H}_{2} \mathrm{O}-\mathrm{NaCl}-\mathrm{CO}_{2}$ inclusions at room temperature.

The calculation program developed in this paper is based on the state equation of a wide temperature and pressure range and high precision, thus it is more applicable than any existing calculation procedures in terms of temperature and pressure condition. The program is suitable for inclusions that are either completely homogeneous to the liquid phase or completely homogeneous to gas phase. Due to the inherent defects of the thermodynamic model, the program has a large $\mathrm{V}-\mathrm{x}$ parameters calculation error for critically homogeneous and near-critically homogeneous inclusions, which requires further improvement.

\subsubsection{Steps for Usage}

The program is provided as Supplementary File S1. The procedure for calculating the V-x value of $\mathrm{H}_{2} \mathrm{O}-\mathrm{NaCl}-\mathrm{CO}_{2}$ inclusions is as follows:

1. Enter the microthermometry measurement parameters required for the calculation, including the partial homogenization temperature of the $\mathrm{CO}_{2}$ phase, the melting temperature of the $\mathrm{CO}_{2}$ clathrates, and the complete homogenization temperature of the inclusions.

2. Select the $\mathrm{CO}_{2}$ phase partial homogenization mode and the inclusion completely homogenization mode, and run the Fortran executive program.

3. The calculation outputs all the seven parameters as shown in Table 2.

\subsection{Calculation Example}

Tables 3 and 4 provide calculation results.

Table 3. Samples for $\mathrm{V}-\mathrm{x}$ parameters of $\mathrm{H}_{2} \mathrm{O}-\mathrm{NaCl}-\mathrm{CO}_{2}$ inclusions (liquid $\mathrm{CO}_{2}+$ vapor $\mathrm{CO}_{2}$ homogenized to vapor phase).

\begin{tabular}{cccccccc}
\hline $\boldsymbol{T}_{\mathbf{h}, \mathrm{CO} 2}$ & $\boldsymbol{T}_{\mathbf{m}, \mathbf{c l a}}$ & $\boldsymbol{T}_{\mathbf{h}}$ & $\boldsymbol{V}_{\mathbf{m}}$ & $\boldsymbol{m}_{\mathrm{CO} 2}$ & $\mathbf{W t} \boldsymbol{\%} \mathbf{N a C l}$ & $\boldsymbol{P}_{\mathbf{h o m}}$ & $\boldsymbol{\Phi}_{\mathbf{C O} 2}$ \\
\hline 298.2 & 280.2 & 473 & 20.92 & 1.948 & 5.678 & 518.2 & 0.1370 \\
298.2 & 278.2 & 473 & 20.74 & 1.757 & 9.004 & 579.7 & 0.1291 \\
298.2 & 273.2 & 473 & 20.46 & 1.437 & 15.47 & 674.8 & 0.1147 \\
293.2 & 280.2 & 473 & 20.94 & 1.846 & 5.678 & 469.9 & 0.1364 \\
293.2 & 278.2 & 473 & 20.77 & 1.660 & 9.004 & 519.5 & 0.1295 \\
288.2 & 280.2 & 473 & 20.94 & 1.814 & 5.678 & 455.5 & 0.1352 \\
298.2 & 280.2 & 523 & 22.74 & 2.564 & 5.678 & 468.0 & 0.2144 \\
298.2 & 278.2 & 523 & 22.34 & 2.302 & 9.004 & 533.3 & 0.1991 \\
298.2 & 273.2 & 523 & 21.69 & 1.864 & 15.47 & 653.5 & 0.1710 \\
293.2 & 280.2 & 523 & 21.28 & 2.348 & 5.678 & 417.3 & 0.2128 \\
293.2 & 278.2 & 523 & 22.40 & 2.111 & 9.004 & 470.7 & 0.1992 \\
293.2 & 273.2 & 523 & 21.79 & 1.720 & 15.47 & 569.1 & 0.1736 \\
288.2 & 280.2 & 523 & 22.78 & 2.231 & 5.678 & 390.9 & 0.2160 \\
288.2 & 278.2 & 523 & 22.43 & 2.000 & 9.004 & 436.4 & 0.1983 \\
288.2 & 273.2 & 523 & 21.84 & 1.620 & 15.47 & 518.6 & 0.1748 \\
283.2 & 280.2 & 523 & 22.78 & 2.147 & 5.678 & 372.7 & 0.2087 \\
283.2 & 278.2 & 523 & 22.45 & 1.917 & 9.004 & 412.0 & 0.1917 \\
283.2 & 273.2 & 523 & 21.88 & 1.530 & 15.47 & 480.6 & 0.1756 \\
278.2 & 280.2 & 523 & 22.78 & 2.108 & 5.753 & 366.3 & 0.2027 \\
278.2 & 273.2 & 523 & 21.90 & 1.478 & 15.47 & 456.6 & 0.1759 \\
273.2 & 280.2 & 523 & 22.91 & 1.991 & 4.333 & 310.7 & 0.2102 \\
273.2 & 278.2 & 523 & 22.52 & 1.797 & 8.483 & 364.2 & 0.1978 \\
298.2 & 280.2 & 573 & 25.51 & 3.525 & 5.678 & 487.2 & 0.3109 \\
298.2 & 278.2 & 573 & 24.52 & 3.061 & 9.004 & 562.5 & 0.2795 \\
298.2 & 273.2 & 573 & 23.00 & 2.322 & 15.47 & 706.9 & 0.2240 \\
293.2 & 280.2 & 573 & 25.60 & 3.142 & 5.678 & 438.6 & 0.3092 \\
293.2 & 278.2 & 573 & 24.71 & 2.759 & 9.004 & 503.6 & 0.2817 \\
\hline
\end{tabular}


Table 3. Cont.

\begin{tabular}{cccccccc}
\hline $\boldsymbol{T}_{\mathbf{h}, \mathrm{CO} 2}$ & $\boldsymbol{T}_{\mathbf{m}, \mathbf{c l a}}$ & $\boldsymbol{T}_{\mathbf{h}}$ & $\boldsymbol{V}_{\mathbf{m}}$ & $\boldsymbol{m}_{\mathrm{CO} 2}$ & $\mathbf{W t}_{\mathbf{H}} \mathbf{N a C l}$ & $\boldsymbol{P}_{\mathbf{h o m}}$ & $\boldsymbol{\Phi}_{\mathbf{C O} 2}$ \\
\hline 293.2 & 273.2 & 573 & 23.28 & 2.132 & 15.47 & 629.8 & 0.2319 \\
288.2 & 280.2 & 573 & 25.64 & 2.891 & 5.678 & 407.4 & 0.3065 \\
288.2 & 278.2 & 573 & 24.81 & 2.552 & 9.004 & 465.1 & 0.2819 \\
288.2 & 273.2 & 573 & 23.45 & 1.988 & 15.47 & 576.1 & 0.2362 \\
283.2 & 280.2 & 573 & 25.65 & 2.700 & 5.678 & 384.0 & 0.3038 \\
283.2 & 278.2 & 573 & 24.87 & 2.387 & 9.004 & 435.4 & 0.2814 \\
283.2 & 273.2 & 573 & 23.58 & 1.864 & 15.47 & 533.2 & 0.2393 \\
278.2 & 280.2 & 573 & 25.65 & 2.603 & 5.753 & 374.1 & 0.3018 \\
278.2 & 273.2 & 573 & 23.66 & 1.769 & 15.47 & 501.8 & 0.2409 \\
273.2 & 280.2 & 573 & 25.49 & 2.422 & 4.333 & 32.24 & 0.3077 \\
273.2 & 278.2 & 573 & 25.06 & 2.168 & 8.483 & 383.2 & 0.2838 \\
298.2 & 280.2 & 623 & 36.71 & 7.756 & 5.678 & 453.4 & 0.5529 \\
298.2 & 278.2 & 623 & 34.05 & 6.616 & 9.004 & 453.8 & 0.5105 \\
298.2 & 273.2 & 623 & 27.12 & 3.822 & 15.47 & 573.2 & 0.3588 \\
293.2 & 280.2 & 623 & 35.64 & 6.135 & 5.678 & 404.3 & 0.5276 \\
293.2 & 278.2 & 623 & 32.66 & 5.109 & 9.004 & 409.4 & 0.4776 \\
293.2 & 273.2 & 623 & 26.56 & 3.092 & 15.47 & 524.5 & 0.3381 \\
288.2 & 280.2 & 623 & 34.65 & 5.072 & 5.678 & 373.1 & 0.5051 \\
288.2 & 278.2 & 623 & 31.52 & 4.165 & 9.004 & 383.2 & 0.4499 \\
288.2 & 273.2 & 623 & 26.31 & 2.674 & 15.47 & 484.9 & 0.3275 \\
283.2 & 280.2 & 623 & 33.82 & 4.331 & 5.678 & 351.1 & 0.4861 \\
283.2 & 278.2 & 623 & 30.68 & 3.541 & 9.004 & 364.6 & 0.4286 \\
283.2 & 273.2 & 623 & 26.14 & 2.376 & 15.47 & 452.7 & 0.3201 \\
278.2 & 280.2 & 623 & 33.32 & 3.970 & 5.753 & 340.8 & 0.4747 \\
278.2 & 273.2 & 623 & 26.03 & 2.165 & 15.47 & 428.4 & 0.3146 \\
273.2 & 280.2 & 623 & 33.83 & 3.575 & 4.333 & 316.5 & 0.4793 \\
273.2 & 278.2 & 623 & 30.17 & 2.926 & 8.483 & 335.8 & 0.4125 \\
\hline
\end{tabular}

Table 4. Samples for $\mathrm{V}-\mathrm{x}$ parameters of $\mathrm{H}_{2} \mathrm{O}-\mathrm{NaCl}-\mathrm{CO}_{2}$ inclusions (liquid $\mathrm{CO}_{2}+$ vapor $\mathrm{CO}_{2}$ homogenized to liquid phase).

\begin{tabular}{cccccccc}
\hline $\boldsymbol{T}_{\mathbf{h}, \mathrm{CO} 2}$ & $\boldsymbol{T}_{\mathbf{m}, \mathbf{c l a}}$ & $\boldsymbol{T}_{\mathbf{h}}$ & $\boldsymbol{V}_{\mathbf{m}}$ & $\boldsymbol{m}_{\mathbf{C O} 2}$ & $\mathbf{W t}_{\mathbf{~} \mathbf{N a C l}}$ & $\boldsymbol{P}_{\mathbf{h o m}}$ & $\boldsymbol{\Phi}_{\mathbf{C O} 2}$ \\
\hline 298.2 & 280.2 & 473 & 20.09 & 3.610 & 5.678 & 1998 & 0.1260 \\
298.2 & 278.2 & 473 & 19.73 & 2.974 & 9.004 & 2159 & 0.1030 \\
298.2 & 273.2 & 473 & 19.44 & 2.326 & 15.47 & 2217 & 0.08207 \\
293.2 & 280.2 & 473 & 19.93 & 3.707 & 5.678 & 2209 & 0.1208 \\
293.2 & 278.2 & 473 & 19.57 & 3.006 & 9.004 & 2384 & 0.09670 \\
293.2 & 273.2 & 473 & 19.31 & 2.354 & 15.47 & 2403 & 0.07735 \\
288.2 & 280.2 & 473 & 19.78 & 3.762 & 5.678 & 2432 & 0.1137 \\
288.2 & 278.2 & 473 & 19.41 & 3.008 & 9.004 & 2397 & 0.08894 \\
298.2 & 280.2 & 523 & 21.19 & 5.296 & 5.678 & 1403 & 0.1942 \\
298.2 & 278.2 & 523 & 20.55 & 4.202 & 9.004 & 1564 & 0.1560 \\
298.2 & 273.2 & 523 & 19.86 & 2.973 & 15.47 & 1770 & 0.1115 \\
293.2 & 280.2 & 523 & 20.98 & 5.473 & 5.678 & 1495 & 0.1885 \\
293.2 & 278.2 & 523 & 20.34 & 4.286 & 9.004 & 1660 & 0.1492 \\
293.2 & 273.2 & 523 & 19.70 & 3.003 & 15.47 & 1863 & 0.1053 \\
288.2 & 280.2 & 523 & 20.79 & 5.613 & 5.678 & 1574 & 0.1819 \\
288.2 & 278.2 & 523 & 20.16 & 4.350 & 9.004 & 1743 & 0.1419 \\
288.2 & 273.2 & 523 & 19.55 & 3.021 & 15.47 & 1947 & 0.09908 \\
283.2 & 280.2 & 523 & 20.63 & 5.721 & 5.678 & 1640 & 0.1758 \\
283.2 & 278.2 & 523 & 20.01 & 4.395 & 9.004 & 1812 & 0.1355 \\
278.2 & 280.2 & 523 & 20.36 & 5458 & 6.409 & 1730 & 0.1610 \\
278.2 & 273.2 & 523 & 19.31 & 3.030 & 15.47 & 1998 & 0.08831 \\
273.2 & 280.2 & 523 & 20.15 & 5.278 & 6.916 & 1801 & 0.1509 \\
273.2 & 278.2 & 523 & 19.70 & 4.141 & 9.904 & 1941 & 0.1182 \\
298.2 & 280.2 & 573 & 22.38 & 7.224 & 5.678 & 1036 & 0.2602 \\
\hline
\end{tabular}


Table 4. Cont.

\begin{tabular}{cccccccc}
\hline $\boldsymbol{T}_{\mathbf{h}, \mathrm{CO} 2}$ & $\boldsymbol{T}_{\mathbf{m}, \mathbf{c l a}}$ & $\boldsymbol{T}_{\mathbf{h}}$ & $\boldsymbol{V}_{\mathbf{m}}$ & $\boldsymbol{m}_{\mathrm{CO} 2}$ & $\mathbf{W t}_{\mathbf{~}} \mathbf{N a C l}$ & $\boldsymbol{P}_{\mathbf{h o m}}$ & $\boldsymbol{\Phi}_{\mathbf{C O} 2}$ \\
\hline 298.2 & 278.2 & 573 & 21.20 & 5.217 & 9.004 & 1157 & 0.1952 \\
298.2 & 273.2 & 573 & 19.70 & 2.703 & 15.47 & 897.4 & 0.09942 \\
293.2 & 280.2 & 573 & 22.07 & 7.423 & 5.678 & 1072 & 0.2521 \\
293.2 & 278.2 & 573 & 20.91 & 5.260 & 9.004 & 1178 & 0.1851 \\
293.2 & 273.2 & 573 & 19.52 & 2.703 & 15.47 & 897.4 & 0.09259 \\
288.2 & 280.2 & 573 & 21.81 & 7.582 & 5.678 & 1103 & 0.2438 \\
288.2 & 273.2 & 573 & 19.38 & 2.703 & 15.47 & 897.4 & 0.08610 \\
283.2 & 280.2 & 573 & 21.59 & 7.707 & 5.678 & 1127 & 0.2365 \\
283.2 & 278.2 & 573 & 20.45 & 5.260 & 9.004 & 1178 & 0.1656 \\
278.2 & 280.2 & 573 & 21.15 & 7.198 & 6.409 & 1173 & 0.2146 \\
278.2 & 273.2 & 573 & 19.15 & 2.703 & 15.47 & 897.4 & 0.07577 \\
273.2 & 280.2 & 573 & 20.85 & 6.862 & 6.916 & 1208 & 0.1996 \\
\hline
\end{tabular}

\section{Conclusions}

The ore-forming fluid of hydrothermal gold ore can be approximated as $\mathrm{H}_{2} \mathrm{O}-\mathrm{NaCl}-\mathrm{CO}_{2}$ system. Therefore, it is important to determine the $\mathrm{V}$-x parameters of $\mathrm{H}_{2} \mathrm{O}-\mathrm{NaCl}-\mathrm{CO}_{2}$ fluid inclusions.

A new algorithm is proposed in this study for the accurate calculation of the $\mathrm{V}$-x parameters of $\mathrm{H}_{2} \mathrm{O}-\mathrm{NaCl}-\mathrm{CO}_{2}$ two-phase inclusions, i.e., inclusions with a $\mathrm{CO}_{2}$ phase homogenization temperature lower than the melting temperature of $\mathrm{CO}_{2}$ clathrate based on microthermometry measurement data.

A calculation program is also developed for the calculation of the $\mathrm{V}-\mathrm{x}$ parameters of the $\mathrm{H}_{2} \mathrm{O}-\mathrm{NaCl}-\mathrm{CO}_{2}$ inclusions. The program uses the new algorithm proposed in this study to calculate the $\mathrm{V}$-x parameters of $\mathrm{H}_{2} \mathrm{O}-\mathrm{NaCl}-\mathrm{CO}_{2}$ two-phase inclusions and uses the improved Parry algorithm to calculate the $\mathrm{V}-\mathrm{x}$ parameters of $\mathrm{H}_{2} \mathrm{O}-\mathrm{NaCl}-\mathrm{CO}_{2}$ three-phase inclusions, i.e., the $\mathrm{CO}_{2}$ phase homogenization temperature is higher than the $\mathrm{CO}_{2}$ clathrate.

Supplementary Materials: The following are available online at http://www.mdpi.com/2075-163X/9/11/673/s1, File S1: calculation program.exe.

Author Contributions: Conceptualization, R.S.; methodology, R.S.; software, X.L.; resources, Z.L.; data curation, J.W.; visualization, J.W.; writing—original draft preparation, S.Y.; writing—review and editing, R.S.; supervision, R.S.; project administration, R.S.; funding acquisition, R.S.

Funding: This research was funded by the National Natural Science Foundation of China (No.41073049).

Acknowledgments: This article is an extension of my project when I was studying in Northwest University, and it under the guidance of Rui Sun. The authors thank Mengjue Wang from Peking University and Jie Zeng from China University of Geosciences (Beijing) for language polishing.

Conflicts of Interest: The authors declare no conflict of interest.

\section{References}

1. Lu, H.Z.; Wang, Z.G.; Li, Y.S. Magma-Fluid Transition and the Genesis of Pegmatite Dike No.3, Altay, Xinjiang, Northwest China. Chin. J. Geochem. 1997, 16, 43-52. [CrossRef]

2. Fyfe, W.S.; Price, N.J.; Thompson, A.B. Fluids in the Earth's Crust; Elsevier: New York, NY, USA, 1979.

3. Liu, J.M.; Chu, X.L.; Liu, W.; Sun, S.H.; Xu, C. Ore-Forming Fluid Systems in Crust. Prog. Geophys. 1997, 12, 31-40. (In Chinese)

4. Liu, C.Q.; Zhang, B.R.; Fu, J.M. Recent Advances in Geochemistry of Geological Fluids/Progress in Geochemistry; Chemical Industry Press: Beijing, China, 2005. (In Chinese)

5. Labotka, T.C. Chemical and Physical Properties of Fluids. Rev. Mineral. 1991, 26, 43-104.

6. Bin, L.; Kun, S. Thermodynamics of Fluid Inclusions; Geological Publishing House: Beijing, China, 1999; Volume 2, pp. 44-72. (In Chinese)

7. Wilkinson, J.J. Fluid Inclusions in Hydrothermal Ore Deposits. Lithos 2001, 55, 229-272. [CrossRef]

8. Chi, G. An Overview on Current Fluid-Inclusion Research and Applications. Acta Petrol. Sin. 2003, 19, 201-212. 
9. Lu, H.Z.; Fan, H.R.; Ni, P.; Ou, G.X.; Shen, K.; Zhang, W.R. Fluid Inclusions; Science Press: Beijing, China, 2004. (In Chinese)

10. Hu, W.X.; Sun, R.; Zhang, W.L.; Sun, G.X. Characteristics of Gold Ore-Forming Fluids and Metallogenic Process by Mutual Mixing and Acting of Deep-Derived Fleids and Shallow-Seeped Ones. Earth Sci. Front. 2001, 8, 281-288. (In Chinese)

11. Chen, Y.J.; Ni, P.; Fan, H.R.; Pirajno, F.; Lai, Y.; Su, W.C.; Zhang, R. Diagnostic Fluid Inclusion of Different Types Hydrothermal Gold Deposits. Acta Petrol. Sin. 2007, 23, 2085-2108. (In Chinese)

12. Duan, Z.; Møller, N.; Weare, J.H. Equation of State for the $\mathrm{NaCl}-\mathrm{H}_{2} \mathrm{O}-\mathrm{CO}_{2}$ System: Prediction of Phase Equilibria and Volumetric Properties. Geochim. Cosmochim. Acta 1995, 59, 2869-2882. [CrossRef]

13. Rui, S.; Dubessy, J. Prediction of Vapor-Liquid Equilibrium and Pvtx Properties of Geological Fluid System with Saft-Lj Eos Including Multi-Polar Contribution. Part II: Application to $\mathrm{H}_{2} \mathrm{O}-\mathrm{NaCl}$ and $\mathrm{CO}_{2}-\mathrm{H}_{2} \mathrm{O}-\mathrm{NaCl}$ System. Geochim. Cosmochim. Acta 2012, 88, 130-145.

14. Duan, Z.; Sun, R. An Improved Model Calculating $\mathrm{CO}_{2}$ Solubility in Pure Water and Aqueous Nacl Solutions from 273 to $533 \mathrm{~K}$ and from 0 to 2000 Bar. Chem. Geol. 2003, 193, 257-271. [CrossRef]

15. Duan, Z.; Sun, R. A Model to Predict Phase Equilibrium of $\mathrm{Ch}_{4}$ and $\mathrm{CO}_{2}$ Clathrate Hydrate in Aqueous Electrolyte Solutions. Am. Mineral. 2006, 91, 1346-1354. [CrossRef]

16. Duan, Z.; Mao, S. A Thermodynamic Model for Calculating Methane Solubility, Density and Gas Phase Composition of Methane-Bearing Aqueous Fluids from 273 to $523 \mathrm{~K}$ and from 1 to 2000 Bar. Geochim. Cosmochim. Acta 2006, 70, 3369-3386. [CrossRef]

17. Song, Y.; Hu, W.; Ni, P.; Duan, Z.; Zhang, X. Improved Method to Determine the Molar Volume and Compositions of the $\mathrm{NaCl}-\mathrm{H}_{2} \mathrm{O}-\mathrm{CO}_{2}$ System Inclusion. Sci. China Ser. D Earth Sci. 2007, 50, 385-391. [CrossRef]

18. Mao, S.; Zhang, D.; Li, Y.; Liu, N. An Improved Model for Calculating $\mathrm{CO}_{2}$ Solubility in Aqueous $\mathrm{NaCl}$ Solutions and the Application to $\mathrm{CO}_{2}-\mathrm{H}_{2} \mathrm{O}-\mathrm{NaCl}$ Fluid Inclusions. Chem. Geol. 2013, 347, 43-58. [CrossRef]

19. Bozzo, A.T.; Chen, H.S.; Kass, J.R.; Barduhn, A.J. The Properties of the Hydrates of Chlorine and Carbon Dioxide. Desalination 1975, 16, 303-320. [CrossRef]

20. Chen, H.S. The thermodynamics and composition of carbon dioxide hydrate. Ph.D. Thesis, Syracuse University, Syracuse, NY, USA, 1972.

21. Diamond, L.W. Stability of $\mathrm{CO}_{2}$ Clathrate Hydrate $+\mathrm{CO}_{2}$ Liquid $+\mathrm{CO}_{2}$ Vapour + Aqueous $\mathrm{KCl}-\mathrm{NaCl}$ Solutions: Experimental Determination and Application to Salinity Estimates of Fluid Inclusions. Geochim. Cosmochim. Acta 1992, 56, 273-280. [CrossRef]

22. Fall, A.; Tattitch, B.; Bodnar, R.J. Combined Microthermometric and Raman Spectroscopic Technique to Determine the Salinity of $\mathrm{H}_{2} \mathrm{O}-\mathrm{CO}_{2}-\mathrm{NaCl}$ Fluid Inclusions Based on Clathrate Melting. Geochim. Cosmochim. Acta 2011, 75, 951-964. [CrossRef]

23. Bakker, R.J.; Dubessy, J.; Cathelineau, M. Improvements in Clathrate Modelling: I. The $\mathrm{H}_{2} \mathrm{O}-\mathrm{CO}_{2}$ System with Various Salts. Geochim. Cosmochim. Acta 1996, 60, 1657-1681. [CrossRef]

24. Duan, Z.; Møller, N.; Weare, J.H. An Equation of State for the $\mathrm{CH}_{4}-\mathrm{CO}_{2}-\mathrm{H}_{2} \mathrm{O}$ System: I. Pure Systems from 0 to $1000{ }^{\circ} \mathrm{C}$ and 0 to 8000 Bar. Geochim. Cosmochim. Acta 1992, 56, 2605-2617. [CrossRef]

25. Pitzer, K.S. Thermodynamics of Electrolytes. I. Theoretical Basis and General Equations. J. Phys. Chem. 1973, 77, 268-277. [CrossRef]

26. Brown, P.E.; Hagemann, S.G. Macflincor and Its Application to Fluids in Archean Lode-Gold Deposits. Geochim. Cosmochim. Acta 1995, 59, 3943-3952. [CrossRef]

27. Bakker, R.J. Package Fluids 1. Computer Programs for Analysis of Fluid Inclusion Data and for Modelling Bulk Fluid Properties. Chem. Geol. 2003, 194, 3-23. [CrossRef]

28. Schwartz, M.O. Determining Phase Volumes of Mixed $\mathrm{CO}_{2}-\mathrm{H}_{2} \mathrm{O}$ Inclusions Using Microthermometric Measurements. Miner. Depos. 1989, 24, 43-47. [CrossRef]

29. Bakker, R.J.; Diamond, L.W. Determination of the Composition and Molar Volume of $\mathrm{H}_{2} \mathrm{O}-\mathrm{CO}_{2}$ Fluid Inclusions by Microthermometry. Geochim. Cosmochim. Acta 2000, 64, 1753-1764. [CrossRef]

30. Diamond, L.W. Review of the Systematics of $\mathrm{CO}_{2}-\mathrm{H}_{2} \mathrm{O}$ Fluid Inclusions. Lithos 2001, 55, 69-99. [CrossRef]

31. Sterner, S.M.; Bodnar, R.J. Synthetic Fluid Inclusions; X, Experimental Determination of P-V-T-X Properties in the $\mathrm{CO}_{2}-\mathrm{H}_{2} \mathrm{O}$ System to $6 \mathrm{~Kb}$ and 700 Degrees C. Am. J. Sci. 1991, 291, 1-54. [CrossRef]

32. Parry, W.T. Estimation of $\mathrm{XCO}_{2}, \mathrm{P}$ and Fluid Inclusion Volume from Fluid Inclusion Temperature Measurements in the System Nacl- $\mathrm{H}_{2} \mathrm{O}-\mathrm{CO}_{2}$. Econ. Geol. 1986, 81, 1009-1013. [CrossRef] 
33. Bowers, T.S.; Helgeson, H.C. Calculation of the Thermodynamic and Geochemical Consequences of Nonideal Mixing in the System $\mathrm{H}_{2} \mathrm{O}-\mathrm{CO}_{2}-\mathrm{NaCl}$ on Phase Relations in Geologic Systems: Equation of State for $\mathrm{H}_{2} \mathrm{O}-\mathrm{CO}_{2}-\mathrm{NaCl}$ Fluids at High Pressures and Temperatures. Geochim. Cosmochim. Acta 1983, 47, 1247-1275. [CrossRef]

34. Xi, B.B.; Shi, W.J.; Zhang, D.H.; Xu, W.G.; Jiang, H.; Wang, C. Improvements and application of iterative Method for Calculating Homogenization Pressure of $\mathrm{H}_{2} \mathrm{O}-\mathrm{CO}_{2}-\mathrm{NaCl}$ Inclusion System. Miner. Depos. 2010, 29, 1138-1144. (In Chinese)

35. Duan, Z.; Sun, R.; Zhu, C.; Chou; Ming, I. An Improved Model for the Calculation of $\mathrm{CO}_{2}$ Solubility in Aqueous Solutions Containing $\mathrm{Na}^{+}, \mathrm{K}^{+}, \mathrm{Ca}^{2+}, \mathrm{Mg}^{2+}, \mathrm{Cl}^{-}$, and $\mathrm{SO}_{2}{ }^{4-}$. Mar. Chem. 2006, 98, 131-139. [CrossRef]

36. Xu, W.G.; Zhang, D.H.; Huang, Z.F.; Xi, B.B.; Fan, H.R. A New Method Used to Calculate the Homogenization Pressure and Related Thermodynamic Parameters of $\mathrm{CO}_{2}-\mathrm{H}_{2} \mathrm{O}$ System at $\mathrm{T}<623.15 \mathrm{~K}$ and $\mathrm{P}<100 \mathrm{MPA}$. Geol. Rev. 2012, 58, 175-182. (In Chinese)

37. Shide, M.; Zhenhao, D.; Wenxuan, H. A Vapor-Liquid Phase Equilibrium Model for Binary $\mathrm{CO}_{2}-\mathrm{H}_{2} \mathrm{O}$ and $\mathrm{CH}_{4}-\mathrm{H}_{2} \mathrm{O}$ Systems above 523K for Application to Fluid Inclusions. J. Supercrit. Fluids 2009, 50, $13-21$.

(C) 2019 by the authors. Licensee MDPI, Basel, Switzerland. This article is an open access article distributed under the terms and conditions of the Creative Commons Attribution (CC BY) license (http://creativecommons.org/licenses/by/4.0/). 